\title{
The Involuntary State/FEEL-LIKE Construction: What Aspect Cannot Do*
}

\author{
Franc Marušič and Rok Žaucer
}

Abstract: The hyperintensional South Slavic involuntary state/FEEL-LIKE construction is interesting in that it is restricted to a peculiar syntactic frame (dative subject and reflexive-impersonal or reflexive-passive verb) but has no overt element encoding its desiderative meaning and its intensionality. Recently it received two very different analyses. For Marušič and Žaucer (2006a), the construction is biclausal, with its desiderative meaning coming from a phonologically null verb. For Rivero (2009), its "modal" meaning arises from a viewpoint-aspect imperfective operator in a monoclausal structure. The aspect-based account poses a challenge for the theory of null verbs, since it cancels what had been considered a rare attestation of the theory's logical possibility of having a null matrix verb. It also poses a challenge for the sententionalist view of hyperintensionality, since it posits that the latter can arise outside a clausal complement. This paper demonstrates that the aspect-based account is problematic in several respects and reinstates the null-verb analysis.

\section{Introduction}

This paper discusses Rivero's recent analysis of the South Slavic FEELLIKE or desiderative Involuntary State Construction (ISC), exemplified in (1).

\footnotetext{
* This paper has benefited greatly from comments of two anonymous reviewers and the editor of $J S L$ as well as from comments from the audiences at FDSL 8 in Potsdam and SLG4/SinFonija 2 in Sarajevo, for which we are grateful. Both authors contributed equally to this work, and the names are listed alphabetically.

References to Rivero are to Rivero 2009. References to our work are to Marušic and Žaucer 2006a unless otherwise specified.
} 
(1) Jušu se pleše $\quad \begin{aligned} & \text { sambo. } \\ & \text { Juš } \\ & \text { DAT }\end{aligned}$ REFL dance samba $_{A S C}$
'Juš feels like dancing the samba.'

(Slovenian)

The striking characteristic of (1) is the fact that the sentence gets a desiderative interpretation even though it contains no overt element encoding desire, ${ }^{1}$ and that this coincides with a peculiar syntactic frame. The obligatory overt formal ingredients comprise a dative nominal, a reflexive clitic, and an indicative verb form with appropriate agreement (in the case of an intransitive verb, default, i.e., 3rd-person-singular-neuter agreement; in the case of a transitive verb, either default agreement cooccurring with an accusative-marked internal argument, as in (1), or passive-style agreement with a nominative-marked internal object; see Marušič and Žaucer 2006a for details). Before Rivero 2009, the construction had received various other analyses, most notably those of Benedicto (1995), Franks (1995), Rivero and Milojević Sheppard (2003), Rivero (2004), and Marušič and Žaucer (2006a). In Marušič and Žaucer (2006a), we argued that the construction involves a phonologically null desiderative verb and is as such biclausal (i.e., contains two VPs, though not two full clausal structures), as in (2a); the null verb is represented in (2a) as FEEL-LIKE in small-caps. The ISC was thus seen as essentially parallel to its overtly biclausal paraphrase, given in (2b), which contains an overt desiderative verb 'feel-like'.

(2) a. [TP [vQP Jušu $\left[\mathrm{vQ}^{\prime}\left[\mathrm{vQ}^{\circ}\right.\right.$ se ] [vp [v $\mathrm{v}^{\circ}$ FEEL-LIKE $][\ldots$ [vP plesJuš $\check{D A T}_{\text {REFL }}$ dance

sambo]]]]]]

$\mathrm{samba}_{A C C}$

'Juš feels like dancing the samba.'

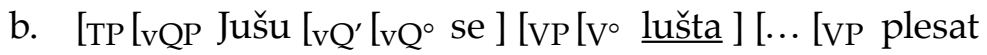
Juš $_{\text {DAT }}$ REFL feels-like dance $_{I N F}$

\footnotetext{
1 We have used the term "dispositional interpretation" in our previous work to describe the kind of desiderative interpretation that is typical of the ISC/FEEL-LIKE construction. Since "dispositional interpretation" is a broader term that may also cover genericity/ability/capacity, we decided to use "desiderativity" instead. We understand this term as covering both a desire in the sense of a mental state, e.g., 'I feel like playing soccer', and urge in the sense of a physiological state, e.g., 'I need to sleep'.
} 
sambo []]]]]

samba $_{A C C}$

'Juš feels like dancing the samba.'

On the other hand, Rivero, incorporating some parts of the analysis in Rivero and Milojević Sheppard (2003) and Rivero (2004), proposes that the "modality"/"intensionality"2 of (1) comes from a viewpoint-aspect imperfective operator (IMPOP) and is interpreted as desire because of the presence of a super-high, TP-embedding Applicative. Unlike (2a) above, Rivero's structure (carried over also in Rivero and Arregui 2012) thus contains a single clause, as in (3) below. ${ }^{3}$

(3)

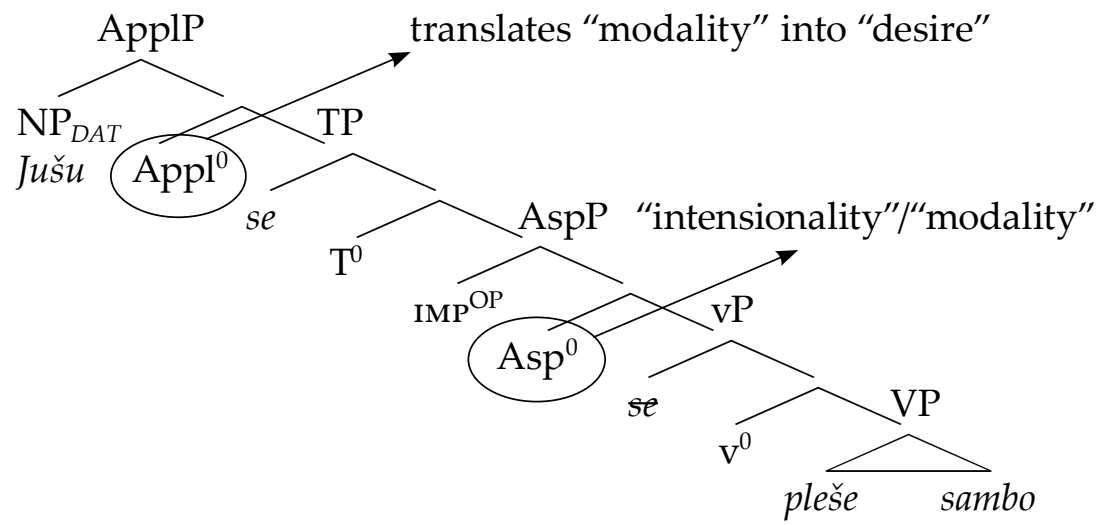

We supported their biclausal analysis with various kinds of data, including the ISC's possibility of hosting conflicting temporal adverbials, as in (4), which they interpreted as evidence for the presence of two independent main events and hence of two VPs (following Larson, den Dikken, and Ludlow's 2006 reasoning about intensional transitive verbs and also of Demirdache and Uribe-Etxebarria 2004).

\footnotetext{
2 Rivero appears to use the terms "modality" and "intensionality" interchangeably to refer to the non-transparent or modal (in its widest sense) nature of the context in question. In this paper we use "modality" as the general term for this property, speaking of desiderative-type modality and futurate-type modality, and reserve the term "intensionality" only for the properties discussed in section 2.4.

3 The graphics that explain how parts of the tree in (3) are interpreted are our addition. At this point, we are also simplifying the details of the reflexive (cf. Rivero 2009: 154), which are not important for our purposes (but see section 4.1 below). One way or another, the reflexive is related to the external argument/SpecvP, either directly, as in (3), or via a null element in SpecvP.
} 


\section{(4) Včeraj se mi ni šlo jutri domov. yesterday REFL $\mathrm{I}_{D A T}$ not-is gone tomorrow home 'Yesterday, I didn't feel like going home tomorrow.'}

Rivero argues, however, that our data do not warrant a biclausal analysis for ISCs since parallel behavior can be observed with English futurates, such as (5), for which Rivero assumes that the structure is monoclausal and that the double adverbials are licensed simply by the futurate interpretation. ${ }^{4}$

(5) For two weeks, the Red Sox were playing the Yankees today.

(Rivero 2009: 153)

In fact, Rivero's analysis of ISC's desire as ultimately stemming from the IMPOP, as in (3), builds on the view that the syntactic source of the futurate interpretation in (5) is also simply its imperfective-like progressive aspect. Rivero sees both the desire of ISCs and the futurate interpretation of futurates as instances of IMPOP-encoded modality, with the former variant arising only in the presence of a super-high ApplP. ${ }^{5}$

Deciding between these competing approaches has consequences that go beyond determining the correct analysis of the ISC. Our analysis of the ISC was important for the larger context of work that posits null verbs (Ross 1976; McCawley 1979; van Riemsdijk 2002, 2012; Marušič and Žaucer 2005, 2006b; Larson, den Dikken, and Ludlow 2006, etc.),

\footnotetext{
4 The assumption that futurates are monoclausal is not uncontroversial. On the one hand, Copley $(2002,2008)$ holds that futurate interpretation originates from a single aspectual head, suggesting futurates' monoclausality. On the other hand, Huddleston (1977) suggests that progressive futurates contain two VPs. Also, Copley and Harley (2009) suggest that causative have is the same thing as Copley's (2008) futurate operator, and Radford (2004: 99-100) claims that causative have is not an auxiliary but a full verb; if Copley and Harley (2009) and Radford (2004) are both correct, futurates should be biclausal.

5 For the most part, Rivero does not go into providing empirical evidence against our analysis or finding technical problems with it. The approach is more one of attempting to show that the proposed alternative analysis can also capture the core data; if it does and if the alternative analysis can be considered to be simpler, it should be superior. In this paper, we argue that the alternative analysis does not capture the data equally successfully, so purported simplicity and conceptual advantages (on which, in our view, the competing analyses cannot be objectively compared anyway) remain irrelevant.
} 
since it claimed to have uncovered the only case that instantiates the approach's theretofore unattested logical possibility of having a null verb as a matrix verb, rather than the more common situation in which a null verb is posited in a subordinate clause. If the correct approach to ISCs is Rivero's aspect-based account, this logical possibility of the null-verb theory may again count as unattested and as such as a potential problem for the null-verb theory (though see also Žaucer 2010). Moreover, whereas on our biclausal account, ISC's hyperintensionality arises in the clausal complement of the null verb, Rivero's monoclausal, aspect-based account has hyperintensionality arise outside a clausal complement, thereby presenting a challenge to the sententionalist view of hyperintensionality (Larson 2002, 2011).

The rest of the paper is organized as follows. Section 2 looks at the parallel that Rivero draws between ISCs and futurates and argues that this leads to several incorrect predictions regarding combinability of futurates and oblique subjects, combinability of futurates and ISCs, aspect restrictions in futurates and ISCs, and hyperintensionality. In section 3, we discuss problems that Rivero faces with respect to ISCs with prefixed verbs (scope relation between the prefix-encoded inception and ISC's modality, prefix as the realization of the modality-encoding IMPOP). In section 4, we present problems for Rivero based on ISCs with modal and aspectual auxiliaries (scope relations between the desire and possibility/necessity modals). Section 5 concludes the paper.

\section{Futurates, Parallels with ISCs, and Problems with the Parallel}

Futurates are interesting in that they allow future interpretations despite the lack of future-tense morphology. Early generative-grammar discussions of futurates include Vetter 1973 and Huddleston 1977, and a recent discussion is found in Copley 2008, which identifies the following properties. Futurates typically have progressive/imperfective verb morphology, and they allow two contradicting temporal adverbials, as in (6). Rivero observes that with respect to both of these features, futurates and ISCs behave in parallel.

(6) a. Today, you are out of the hospital in a week (but if something goes wrong during your operation tomorrow, you might have to stay here longer).

(Marušič and Žaucer 2006a: 1100) 
(6) b. Yesterday, John was getting married tomorrow.

(Copley 2011, (6a))

Semantically, futurates typically convey that there is a plan for an event to take place in the future (Copley 2008). This modal character also makes futurates similar to ISCs: they describe an event that has not yet taken place. According to Copley, futurates describe plans because of the presence of a presupposition that assigns control over the intended event to a "director," i.e., an entity that makes sure the plan is carried out; the director is supplied contextually, and can but need not be the same as the subject. In the following subsections, we will test the parallel that Rivero draws between futurates and ISCs.

\subsection{Directors Need Not Be Blocked by Oblique Subjects: Oblique Subjects and Futurates}

Rivero posits that futurates and ISCs differ in the type of modal interpretation. Futurates have a nominative subject and a director, i.e., an entity with control over the intended event, which can be the same entity as the nominative subject, though it need not be, as the director can also be supplied from the context; this yields the modal meaning of a plan (2009: 157). ISCs, on the other hand, have an oblique subject, which cannot act as a director since obliques are incompatible with control, and which also prevents entities present in the context from acting as directors (2009: 154, 173). As a result, ISCs denote a plan without a director, which-it is assumed-can be understood as a desire (2009: 157). According to Rivero, this falls out from her syntactic structure for ISCs, which contains a TP-embedding applicative with a dative argument; see (3) above.

This aspect of Rivero's proposal brings us to the first problem. If the director cannot be assigned from the context because it is blocked by the presence of the dative oblique subject, we would expect that in any oblique-subject construction that could otherwise potentially get a futurate reading, the oblique (experiencer) subject will block the assignment of a director from the context. That is, given that the modality is seen as originating in AspP and the oblique (experiencer) subject as blocking contextual assignment of a director and as triggering the translation of the modality into a desiderative interpretation, we predict that in any sentence with an oblique (experiencer) subject, an attempt to get a futurate interpretation will automatically result in 
a desiderative reading. ${ }^{6}$ This prediction is, however, not borne out, as shown in (7), which contains a dative-subject experiencer predicate and does not have a desiderative interpretation but rather a regular futurate interpretation.

(7) [Context: Because he is afraid of the dark, Peter always feels sick when the sun sets.]
A: Kdaj je
pol Petru jutri
slabo?
when AUX then Peter $_{D A T}$ tomorrow bad
(Slovenian)

'So what time is Peter feeling sick tomorrow?'
B: Jutri mu je očitno slabo ob 18:20.
tomorrow him DAT $_{\text {AUX apparently bad at 18:20 }}$

'Tomorrow he's feeling sick at 18:20.'

(Impossible: 'Tomorrow he will feel like feeling sick at 18:20.')

Note that futurates of statives are usually not as natural as futurates of dynamic predicates such as 'play the Yankees', but provided an appropriate context, they are often grammatical., 8

\footnotetext{
6 In this respect, Rivero 2009 differs importantly from Rivero and Milojević Sheppard 2003, where the TP-dominating phrase not only introduces the dative argument but also the modality (and is hence labeled ModalP rather than ApplP), a function which Rivero assigns to AspP.

7 A reviewer notes that it is not clear that sentences like (7), even though future-oriented, are futurates; they differ from the futurate in (5) in lacking an obvious director and plan. In Copley's approach to futurates (Copley 2002, 2008, Copley and Harley 2009, Błaszczak and Klimek-Jankowska 2013), which is the approach adopted by Rivero 2009; cf. examples like (i), which lack a director as does our (7), also fall under futurates.
}

(i) The Sun rises tomorrow at 6:30.

Sentences like (i) do not involve plans overseen by animate directors but rather natural laws. As Copley (2002: 55) puts it: “When there is no animate director, let's say, law-like properties true of the world-time pair in question entail that other law-like properties of the world-time pair determine whether $\mathrm{p}$. It may thus make a certain amount of sense to speak of the world as a 'director.'" Błaszczak and Klimek-Jankowska (2013: 14) similarly claim that the plan should be understood in a broad way in these cases, as "a concrete plan or arrangement, a timetable, or a plan 'designed' by the nature (e.g., sunrises and sunsets, tides, etc.)." Rivero (2009: 170, fn. 8) also mentions futurates without a director and a proper plan, stating that such examples, which she reports to be known also in the Bulgarian grammatical tradition (see Tilkov et al. 1982-83), "involve certainty based on previous knowledge, or an authoritative point of 
The fact that sentences such as (7) are acceptable with a futurate reading is a problem for Rivero in two ways. Since dative/oblique subjects are claimed by her to be incompatible with control and hence not to qualify for directors, and since their presence is supposed to block the director from being defined in the context (2009: 154), sentences like (7) should-in her system-simply not be able to get a futurate interpretation, just as ISCs cannot. Or from a slightly different angle, the problem is that according to her, as soon as a sentence with a dative/oblique experiencer subject contains the futurate-deriving modality, the latter will automatically translate into a desiderative interpretation. However, as shown in (7), when such sentences are acceptable, they are only acceptable on a futurate interpretation and cannot get a desiderative reading (i.e., they cannot be an ISC).

In short, given the nature and role it presupposes for directors and oblique subjects, Rivero's account of ISCs should, contrary to what (7) reveals to be the case, prevent sentences with dative/oblique experiencer subjects from having futurate readings; as soon as (7) were interpretable with the futurate/ISC modality, it could only be interpretable as an ISC. On the other hand, our account of ISCs is independent of futurates and consequently does not make any such incorrect predictions with respect to sentences like (7).

\subsection{Combining Futurates and ISCs}

Rivero argues that despite differences in semantic details, the modal interpretation of futurates (i.e., plan) and the modal interpretation of ISCs (i.e., desire) both stem from the viewpoint-aspect operator (IMPOP). The difference lies only in the extra TP-embedding dative argument, which prevents the modal interpretation of plan and forces that of desire.

view to the effect that the intended action will take place." So both in Rivero 2009 and in the line of work followed by that work, directors and narrowly understood plans do not seem to be a necessary condition for futurates and, if examples like (i) are taken to be futurates, examples like (7) should also count as futurates. Note also that while (7) may get a meaning that is intuitively closer to 'it seems that' than to 'there is a plan that', this can just as well be seen as a variant of 'there was a plan that' with something like destiny or the natural course of events as the director, in line with the discussion in this footnote (cf. also English (6a) above).

${ }^{8}$ Just as futurates of statives are usually not as natural as futurates of dynamic predicates but are nonetheless often possible when in an appropriate context, the same goes for ISCs based on statives. This may be related to the fact that it is not easy to imagine that there exists a plan that someone's desire to do something would take place. 
Placing the basic ingredient of futurates and ISCs in the same projection makes another clear prediction (as does the posited incompatibility of the dative subject and the modal interpretation of plan): there should be no futurate ISC, that is, the futurate and the desiderative interpretation should be in complementary distribution and should thus never coocur. However, as we discussed (2006a: 1101), this prediction is incorrect. One such example is given in (8) (cf. fnn. 7 and 8).

(8) Včeraj se $\mathrm{mi}$ danes še ni šlo $\mathrm{v}$ hribe. (Slovenian) yesterday REFL $\mathrm{I}_{D A T}$ today still not gone to mountains 'Yesterday, it did not seem that I would feel like going to the mountains today.' (besides the also possible non-futurate ISC interpretation: 'Yesterday, I did not feel like going to the mountains today.')

Given that the combination of the futurate construction and the ISC is possible, the futurate modal and the desiderative modal interpretation cannot, contrary to Rivero, originate in the same viewpoint-aspect projection. Also, as already established with a non-ISC oblique-subject predicate in section 2.1 above, oblique subjects and the futurate cannot be mutually exclusive.

On the other hand, our account of ISCs is independent of futurates and thus faces no problems due to the availability of futurates of ISCs, such as (8). Whatever it is that licenses the futurate interpretation in an ordinary/non-ISC sentence, including the overt paraphrase of the ISC, can also license the futurate interpretation in an ISC.

\subsection{Different Aspect Restrictions on Futurates and ISCs}

By deriving the modality of both futurates and ISCs from the imperfective operator, Rivero predicts that futurates and ISCs will be subject to the same restrictions, if any, with respect to the aspectual value of their input. So, given that Rivero (2009: 182-83) claims that Slovenian ISC cannot be built on perfective predicates, the proposal predicts that Slovenian will also not allow futurates with perfective predicates.

This is, however, not the case, as shown in (9) (the perfectivity of odpotujem can be confirmed with standard tests for (im)perfectivity, such as its incompatibility with durative adverbials, non-embeddability under phase verbs, etc.; cf. Borik 2006). 
(9) Jutri odpotujem v Potsdam.
tomorrow depart $_{P F}$ to Potsdam
'I leave for Potsdam tomorrow.'

(Slovenian)

Now there may be some disagreement with respect to the grammaticality of perfective ISCs. Unlike Rivero, we claim (2006a: 1144-46) that in certain contexts these are possible (marginal grammaticality is also acknowledged for such cases in Rivero and Milojević Sheppard 2008: 280, fn. 4). Such contexts, however, would not include cases like odpotujem $v$ Potsdam in (9), which means that this special-case character cannot be invoked as a way out of the incorrect prediction that Rivero makes with respect to aspectual restrictions on ISCs and futurates. ${ }^{9}$ Moreover, Rivero's account crucially relies on the ungrammaticality of perfective predicates in Slovenian ISCs, and as such it cannot accommodate our "restricted-context" perfective ISCs either.

\subsection{Hyperintensionality}

Rivero (2009: 164-65, fn. 5) claims that English futurates and ISCs behave in parallel with respect to intensionality and hyperintensionality. We will try to show that this claim is not quite correct, which then presents another unrealized parallel and consequently a challenge to her account of ISCs.

There are three standard tests for hyperintensional or opaque contexts (see Larson 2002) that go back to Frege: indefinite DPs need not be interpreted as specific, non-referring terms need not yield falsity, and substitution of coreferring terms need not preserve truth. Futurates and ISC behave alike only on one of these tests, that is, only with respect to indefinite DPs.

\footnotetext{
9 Rivero's account could perhaps be understood as subsuming under futurates only future-oriented present-morphology predicates with progressive/imperfective aspect, in which case the perfective-marked predicate in (9) would not count as a futurate despite its future orientedness and present morphology. If so, it would not attest to an incorrect prediction on the part of Rivero. However, according to Copley (2002, 2008) - the approach adopted by Rivero-futurates are not restricted to progressives (cf. also fn. 7), so (9) must also count as a futurate and thus as containing Copley's $(2002,2008)$ futurate operator/modal operator PLAN and by extension Rivero's IMPOP. Cases like (9) therefore remain relevant as a valid attestation of the incorrect prediction of Rivero with respect to aspect restrictions on the input to ISCs and to futurates.
} 
As for the interpretation of indefinite DPs, an indefinite DP in an extensional/transparent context shows no ambiguity. The indefinite DP in (10a) can only be read specifically. On the other hand, an indefinite DP in an intensional context is ambiguous, so that a famous actress in (10b) can be read either specifically or nonspecifically.

(10) a. Jim met a famous actress.

b. Jim believed [ $\mathrm{CP}$ a famous actress was in the movie].

As shown in (11) and (12), an indefinite DP can indeed be read non-specifically in both ISCs and futurates, as pointed out by Rivero.

(11) Petri se je poljubljalo enega profesorja. (Slovenian) Petra $_{D A T}$ REFL AUX kissed one professor

'Petra felt like kissing a professor.'

(12) For two weeks Susan was marrying a professor next year.

(Rivero 2009: 165, fn. 5)

However, this turns out to be the only test in which the two constructions clearly pattern alike. Moreover, on its own, availability of a nonspecific reading can actually be a sign of either hyperintensionality or only weak intensionality, but we showed (2006a: 1142-43) ISCs to be not only weakly intensional but hyperintensional. ${ }^{10}$ Indeed, a nonspecific reading by itself will also be available if the same predicate from (12) - Susan marry a professor -is embedded under future tense, (13), or with possibility or necessity modals (cf. M\&Ž: 1143), both of which are known to create weakly but not hyperintensional contexts.

(13) Susan will Marry a professor next year.

10 Following Kearns (2000), among others, intensionality comes in two types divided by the tests they pass. Whereas hyperintensional (also strongly intensional) contexts pass all three of the tests mentioned above, weakly intensional contexts only clearly exhibit the non-specific reading of indefinite noun phrases. Based on this, the literature also distinguishes between want-type verbs (which is where FEEL-LIKE and other desire predicates fit) and necessity/possibility modals. The former, unlike the latter, are said not to introduce a type of modality/modal force (cf. Kratzer 1991, Kearns 2000) but are rather propositional attitude-report predicates (cf. Heim 1992, Larson 2002). 
Citing (12) as evidence that futurates are intensional just like ISCs, as does Rivero, will therefore not be enough, and we need to contrast the two constructions with further intensionality tests.

The second commonly cited property of opaque/intensional contexts is the presence of a non-referring term. In hyperintensional contexts such terms need not yield falsity. Example (14a) can be true despite the fact that there are no unicorns in our world, but in the extensional context of (14b), a non-referring term necessarily yields falsity. Because there are no unicorns in our world, a sentence like (14b) must be false.
a. Jim believed [CP he saw a unicorn cross-country skiing].
b. Jim met a unicorn.

In ISCs, the use of non-referring terms is comparable to verbs of attitude report, that is, ISCs behave like proper intensional contexts.

Petru se je šlo $\mathrm{v}$ Potsdam na leteči (Slovenian) Peter $_{D A T}$ REFL AUX gone to Potsdam on flying preprogi, čeprav ve, da take preproge ne obstajajo. carpet although knows that such carpets not exist 'Peter felt like going to Potsdam on a flying carpet even though he knows that such carpets do not exist.'

Judgments are somewhat less clear with futurates. In the futurate counterpart of (15), the use of a nonexisting term yields falsity, as in (16).

(16) \#Yesterday Peter was flying to Potsdam tomorrow on a flying carpet, even though he knows/everyone knows/it's widely known/god knows that flying carpets don't exist.

Example (16) can be uttered truthfully if the sentence is continued with something like 'but then he realized that flying carpets don't exist'. In this case, however, the truth of the first part of the sentence is evaluated relative to an alternative world, not to the world where flying carpets do not exist. The same applies to Rivero's example in (17), for which she notes that it is a natural report of some child's dream that lasted for two weeks; in this case, the truth of the first part of the sentence is evaluated relative to an alternative world. 
(17) For two weeks Susan was adopting a unicorn next year, and then found out that there are no unicorns.

(Rivero 2009: 165, fn. 5)

To be fair, we do not find the data very clear, since it is not obvious how to evaluate the truth of a futurate. If every futurate were paraphrasable with ' $X$ plans to $Y^{\prime}$ ', then the only way to evaluate them would be to ask person $X$. However, futurates are not always paraphrasable in such a way. As Copley (2008) puts it, there is a plan that $\mathrm{Y}$ will happen and $\mathrm{X}$ as the director sees that this happens. Therefore, knowing that the New York Mutuals baseball team ceased to exist more than 130 years ago, uttering a sentence like (18) today does not make much sense; in this, futurates and ISCs with non-referring terms (as in (15) above) part ways.

(18) \#The Yankees are playing the Mutuals tomorrow.

The third test is substitution of a coreferring term. In extensional/transparent contexts, such a substitution necessarily preserves the truth value of the proposition, whereas in an intensional/opaque context, it need not preserve the truth value. Examples (19) through (21) present a regular transparent context, an ISC, and a futurate construction (in that order).

(19) The Sens beat the Habs. $\rightarrow$ The Sens beat the Canadiens. ${ }^{11}$

(20) Včeraj se je Sensom igralo jutri s yesterday REFL AUX Sens played tomorrow with

Canadiensi.

Canadiens

'Yesterday the Sens felt like playing the Canadiens tomorrow.'

$\nrightarrow$ Včeraj se je Sensom igralo jutri s yesterday REFL AUX Sens played tomorrow with Habsi.

Habs

'Yesterday the Sens felt like playing the Habs tomorrow.'

$\overline{11}$ The Habs is a nickname for the NHL team officially called the Montreal Canadiens. 
(21) Yesterday, the Sens were playing the Canadiens today (but the schedule has changed).

$\rightarrow$ Yesterday, the Sens were playing the Habs today (but the schedule has changed).

The futurate construction in (21) patterns with the regular transparent context in (19); that is, substitution of coreferring terms necessarily preserves truth in both. In ISCs, on the other hand, truth need not be preserved.

In short, then, ISCs and futurates do not behave alike with respect to intensionality/opacity, contra Rivero; they clearly differ at least on the test with substitution of coreferring terms and-admittedly with some lack of clarity-also on the test with non-referring terms.

To wrap up section 2, we have argued that Rivero's posited parallel between futurates and ISCs and her futurate-based IMPOP account of ISCs are problematic in several ways. We have shown that it makes incorrect predictions with respect to combinability of futurates and oblique subjects, combinability of futurates and ISCs, aspect restrictions in futurates and ISCs, and hyperintensionality. Another puzzle her account would have to address is why there exist languages such as Spanish which have a futurate-deriving aspect (in Spanish the socalled Imperfecto, according to Rivero), oblique experiencer subjects, and the reflexive clitic with the necessary use(s), yet they nevertheless do not exhibit the ISC. None of these issues, on the other hand, are problematic for our null-verb account.

\section{Prefixes}

Slavic languages exhibit a vast array of verbal prefixes, often quite comparable to particles in Germanic particle verbs (see Spencer and Zaretskaya 1998, Svenonius 2004). Some of these prefixes participate in ISCs in revealing ways. We will limit this discussion to the "inceptive" use of prefixes, an instance of which is shown in an ordinary/non-ISC structure in (22).

$$
\begin{aligned}
& \text { a. voleti Mariju } \\
& \text { love Marija } \\
& \text { 'love Marija' }
\end{aligned}
$$

b. za-voleti Mariju behind-love Marija 'come to love Marija'

(Serbian) 
In Bosnian/Croatian/Serbian and Bulgarian (but not Slovenian), the verb in an ISC can contain an "inceptive" prefix, and in Bulgarian also a "terminative" prefix (as we note in 2006a: 1127-31).
a. Pri-spalo mi se. at-slept $\quad \mathrm{I}_{D A T}$ REFL
'I started to feel like sleeping.'
b. Pri-jele su mi se jabuke.
at-ate AUX $\mathrm{I}_{D A T}$ REFL apples
'I started to feel like eating apples.'

(Serbian)

We analyze the inceptive prefix in (23) as syntactically belonging to the phonologically null verb (pri-FEEL-LIKE), as shown in (24), although attached to the overt verb on the surface (pri-spa-) (for the sake of simplicity, we can ignore the original position of the prefix inside the matrix clause; see our 2006a article for details of the derivation). ${ }^{12}$

(24) [Clause1

$$
\begin{aligned}
& \text { pri-FEEL-LIKe mi se [Clause2 ... [vP spa- ]]] } \\
& \text { at-FEEL-LIKE } \mathrm{I}_{D A T} \text { REFL sleep }
\end{aligned}
$$

Rivero, on the other hand, posits no null verb, so the prefix must be part of the same clause as the overt verb, combining with the overt verb not just phonologically but also syntactically. Notice, however, that as indicated in the translation in (23), pri- does not mark the inception of the event described by the verb but the inception of the desire. Given Rivero's structure, where the desire only arises at the very end of clausal composition with the ApplP, this is already surprising, as the desire should then have scope over the inception. Moreover, Rivero's analysis faces other problems as well.

Rivero claims that the inceptive pri- instantiates the imperfective operator (IMPOP) which is the source of modality (2009: 178). We see at least four problems with this claim. First, dropping the prefix removes the inception but not the modality (desire), as seen in (25), so the modality clearly cannot be encoded by the prefix.

\footnotetext{
12 A similar proposal is made by van Riemsdijk (2002), who suggests that the phonologically null verb go in Dutch can occur in a particle-verb construction with an overt particle aan 'on'.
} 


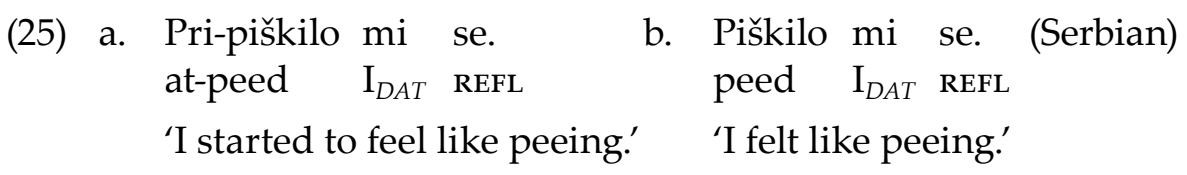

Second, most prefixation, including inceptive prefixation, is known to trigger a change in aspect, as seen in (26). Whereas voleti Mariju in $(26 a-b)$ is interpreted imperfectively, as evidenced by the fact that it allows durative adverbials and embeds under phasal verbs (cf. Borik 2006), za-voleti Mariju in (26c-d), in which a prefix has been added to the same verb, is interpreted perfectively, as evidenced by the fact that it disallows durative adverbials and does not embed under phasal verbs.

$$
\begin{aligned}
& \text { a. voleti Mariju (5 minuta) } \\
& \text { love Marija } 5 \text { mins } \\
& \text { 'love Marija (for } 5 \text { minutes)' } \\
& \text { b. (početi/prestati) voleti Mariju } \\
& \text { begin/cease love Marija } \\
& \text { '(begin/cease) to love Marija' } \\
& \text { c. za-voleti Mariju ( }{ }^{*} 5 \text { minuta) } \\
& \text { behind-love Marija } 5 \text { minutes } \\
& \text { 'come to love Marija ( }{ }^{*} \text { for } 5 \text { minutes)' } \\
& \text { d. ('početi/prestati) za-voleti Mariju } \\
& \text { begin/cease behind-love Marija } \\
& \text { '(*begin/cease) to come to love Marija' }
\end{aligned}
$$

Since Bulgarian and Serbian pri-, which marks the inception of the desire, is claimed by Rivero to instantiate the imperfective operator, one would expect the whole ISC to behave as imperfective. However, whereas prefixless ISCs behave like regular imperfectives in allowing durative adverbials, as seen in (27a-b), and embedding under phasal verbs, as seen in (28a-b), ISCs with inceptive pri- are not at all compatible with durative adverbials, as seen in (27c), and do not embed under phasal verbs, as seen in (28c); this is unexpected if, as per Rivero, ISCs with inceptive pri- were indeed imperfective. If these forms were imperfective, they would be the only imperfectives not allowing durative adverbials and not embedding under phasal verbs. 
(27) a. Piškio sam 5 minuta.

(Serbian)

peed AUX 5 minutes

'I was peeing for 5 minutes.'

b. Piškilo $\mathrm{mi}$ se 2 sata.

peed $\mathrm{I}_{D A T}$ REFL 2 hours

'For 2 hours I felt like peeing.'

c. *Pri-piškilo mi se 2 sata.

at-peed $\mathrm{I}_{D A T}$ REFL 2 hours

(28) a. Počeo sam piškiti.

began AUX pee

(Serbian)

'I began to pee.'

b. Počelo mi se piškiti.

began $\mathrm{I}_{D A T}$ REFL pee

'I began to feel like peeing.'

c. *Počelo mi se pri-piškiti.

began $\mathrm{I}_{D A T}$ REFL at-pee

Third, if modality comes from the prefix as claimed by Rivero, we should be able to omit the dative nominal and still get modality-albeit a futurate instead of a desire (the IMPOP-realizing prefix is there; the futurate to desiderative-translating ApplP, which hosts the dative argument, is removed). This is not the case, however. As a consequence, in cases where the combination of the prefix and the verb does not exist outside the ISC, what we get is simply ungrammatical, regardless of adverbials that try to set up a futurate, as shown in (29). ${ }^{13}$

13 Note that the ungrammaticality of (29) could not be due to there being no nominative subject/agent, given that such a sentence is fine if it has no prefix, shown in (i), and that it is equally impossible if it does have a nominative subject/agent, as shown by (30).

(i) a. Piškilo se. peed REFL

(Serbian)

'People were peeing.' / 'There was peeing taking place.'

b. Jele su se jabuke.

ate AUX REFL apples

'Apples were being eaten.' 


\section{(29) a. *Pri-piškilo se. at-peed REFL}

(Serbian)
b. *Pri-jele su se jabuke. at-ate AUX REFL apples
c. *Prije dve sedmice pri-jele su se jabuke juče. before two weeks at-ate AUX REFL apples yesterday

Fourth, if as per Rivero the inceptive prefix pri- from (23) syntactically attaches directly onto the verbs piškiti and jesti, as a VP-external functional projection, we predict that we will also find this combination of the prefix and the verbs aside from ISC and aside from impersonal/passive/non-active se sentences. This prediction is not borne out, as seen in (30) (cf. M\&Ž: 1130, fn. 28).

$$
\begin{aligned}
& \text { *Petar je pri-jeo jabuke/ pri-piškio. } \\
& \text { Peter AUX at-eat apples at-pee }
\end{aligned}
$$

(Serbian)

For us, pri-syntactically belongs to the null verb FEEL-LIKE, which brings with it both the dative and the non-active se, like many other experiencer verbs including the verb in the ISC's overt paraphrase from (2b) above. And given that idiosyncratic lexical restrictions are not uncommon with verb-prefix combinations, it need not be surprising that there is such a restriction also in the case of pri- and FEEL-LIKE, that is, that there is a verb pri-FEEL-LIKE and that there is no verb pri-jesti (see our 2006a article for a longer justification of this claim). As far as we can see, this remains a mystery for Rivero: if pri- heads AspP in the extended projection of the verb jesti in the ISC, it is not clear why it could not do so beyond the ISC.

As this section has shown, Rivero's account makes four separate predictions regarding prefixed ISC that are not borne out. As we made clear (2006a: 1127-31) and the discussion above, our null-verb approach faces no problem with prefixed ISC data.

\section{Modal and Aspectual Verbs}

This section tests Rivero's analysis of ISCs as regards scope relations between the desire on the one hand and modal or aspectual auxiliaries on the other. We show that Rivero's proposal predicts that in ISCs there should be only one possible scope relation between the desire and 
necessity/possibility modal verbs and only one possible scope relation between the desire and aspectual verbs. We present data which show that this prediction is incorrect.

Root modals are typically seen as originating below TP and above any AspPs (unlike epistemic modals, which are above TP) (see Butler 2003, Cinque 1999). Combining this view with Rivero's structure for ISCs, an ISC with a root modal should thus have the structure in (31).

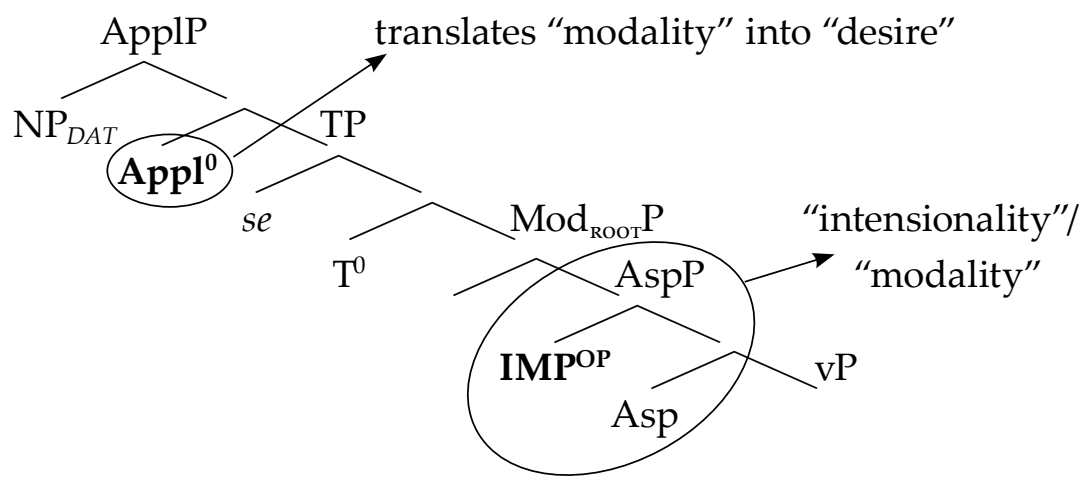

If root modals have a fixed position in sentential structure, and if the desire of an ISC also originates at a specific syntactic position, we get a clear prediction: the two elements should be in a fixed-scope relation.

Now the two key elements in Rivero's desiderative interpretation of ISCs are the TP-embedding applicative and the imperfective operator in the specifier of AspP. As sketched in (31) above, the modality of ISCs is introduced with the IMPOP, but the desire in a sense comes via ApplP; that is, the modality of the IMPOP is interpreted as desire because of the presence of the ApplP. This may leave some doubt as to which of these two projections such an analysis associates the desire with, ApplP or AspP, so we will discuss each option in turn. If-given that the ApplP is responsible only for changing the type of modal interpretation introduced by the IMPOP, not for introducing it-we interpret Rivero as claiming that the desire originates in the aspectual operator, then we should not find a root modal scoping under the desire. And if-given that it is the presence of the ApplP in the structure that allows the desiderative interpretation-we interpret Rivero as claiming that the desire is associated with the ApplP, then we should not find a root modal scoping over the desire. Importantly, whichever option we go with, we predict only one possible scope relation between the root modal and the desire. 
This prediction, however, is not correct. As we point out (2006a: $1121)$, a root modal in an ISC can scope both under and over the desire, as seen in (32).

(32) Joni se sme igrat fuzbal. Jona $_{D A T}$ REFL can play $_{I N F}$ soccer

(Slovenian)

a. 'Jona is allowed to feel like playing soccer.'

"allowed > feel-like"

b. 'Jona feels like being allowed to play soccer.'

"feel-like > allowed"

Note that unlike Rivero's, our account explains the ambiguity in (32) straightforwardly. Recall from (2a) above that our structure for ISCs has two clauses, with the desire coming from the matrix verb. Since it has two clauses, the account also has two positions for the same root modal, one as part of the matrix clause and one as part of the lower clause. When the root modal in (32) scopes over the desire, it is a modal of the matrix clause, as seen in (33).

(33)

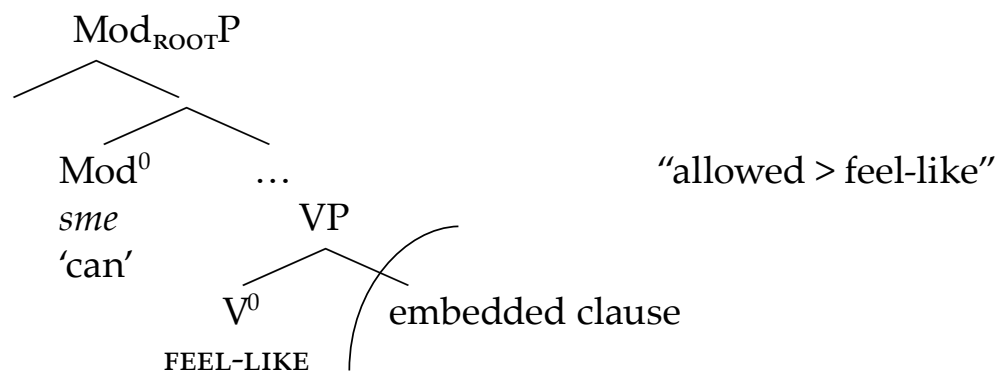

And when the root modal in (32) scopes under the desire, it is a modal of the embedded clause, as in (34).

(34)

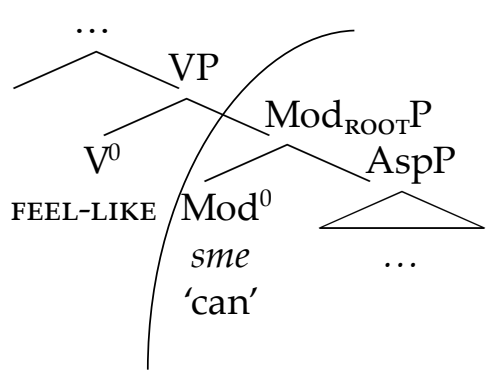

"feel-like > allowed" 
We observe (2006a: 1122-23) the same kind of scopal ambiguity also between aspectual verbs and the desire, shown in (35), which can be used to make the same point.

(35) Yankeejem se je začenjalo igrat finalno serijo. Yankees $_{D A T}$ REFL AUX began play ${ }_{I N F}$ final series

(Slovenian)

a. 'The Yankees began to feel like playing the World Series.' "begin > feel-like"

b. 'The Yankees felt like beginning to play the World Series.' "feel-like > begin"

If aspectual verbs have a fixed position in the clausal structure (see Cinque 2004) as does Rivero's IMPOP, then a monoclausal account such as Rivero's predicts that the desire and a particular aspectual verb, such as 'begin' in (35), will be in a fixed scope relation. As shown by (35), this prediction is incorrect. On the other hand, our biclausal account explains the observed ambiguity straightforwardly: the reading under (35a) arises when 'begin' is in an aspectual projection of the matrix clause ([Aspinceptive $\mathrm{P}$ 'begin' [VP1 FEEL-LIKE [ VP2 ]]]), and the reading under (35b) arises when 'begin' is in an aspectual projection of the lower clause ([VP1 FEEL-LIKE [AspinceptiveP 'begin' [ VP2 ]]]).

Another related feature of ISC is the three-way ambiguity observed with cooccurrence of often and non-stop in ISCs (2006a: 1117-21), which our biclausal account explains with [... often non-stop FEEL-LIKE [ VP2 ]], [... FEEL-LIKE [often non-stop VP2]] and [often FEEL-LIKE [non-stop VP2]]. As far as we can see, Rivero's account cannot explain such data.

\subsection{Scope Relations and the Position of the Reflexive}

As pointed out by a reviewer, it may be at first sight surprising that despite the fact that the reflexive, which is known to be an obligatory part of ISCs, precedes the possibility modal in (32), repeated below. Example (32) shows two readings with respect to the relative scope of the possibility modal and the desire. This boils down to the question of whether se's surface position should not have an effect on the scoping possibilities. 
(32) Joni se sme igrat fuzbal.

(Slovenian) Jona $_{D A T}$ REFL can play $_{I N F}$ soccer

a. 'Jona is allowed to feel like playing soccer.'

"allowed > feel-like"

b. 'Jona feels like being allowed to play soccer.'

"feel-like > allowed"

First, as we have noted, se is an obligatory part of the ISC but it is not responsible for the presence of the desiderativity, as it is just an argument suppressor or marker of non-active morphology, i.e., the element that makes the desiderative predicate of ISCs an unaccusative desiderative predicate. The surface order of se and the modal verb in (32) should thus not have any effect on the scope of the desiderative predicate and the ability/permission modal.

Second, in Rivero and Milojević-Sheppard's (2003) analysis of se, which is adopted in Rivero, se is the subject/agent of the clause/event and should as such also not contribute any desire. So if (32), as well as (35) above, were nonetheless seen as problematic for us (i.e., the analysis we are contrasting with Rivero's), it should be equally problematic for Rivero and thus cannot be used as evidence for or against one of the two proposals.

Third, for us se is an argument-suppressing clitic which gets placed in the Wackernagel position with its place of origin concealed. Even if one claims that se is part of the desiderative interpretation, becoming so via the argument/event structure changes which it causes (cf. Kallulli 2006), it still holds that it is a clitic and is as such subject to total reconstruction (cf. Marušič 2008). In fact, comparing the ISC and its overt-verb counterpart as we have systematically done (cf. (2) above), we note that in the overt desiderative-verb counterpart of ISC, which also has an unaccusativity-marking reflexive clitic associated with the desiderative predicate and in which the two scopes of the desiderative predicate and the ability/permission modal will pattern with inverse surface orders of these two elements, the reflexive clitic is also found in its Wackernagel position, preceding both the desiderative predicate and the ability/permission modal, as shown in (36):

$\begin{array}{llllll}\text { a. Joni } & \text { se } & \text { sme luštat } & \text { igrat } & \text { fuzbal. (Slovenian) } \\ \text { Jona }_{D A T} & \text { REFL } & \text { can feel-like } & \text { fNF } & \text { play }_{I N F} & \text { soccer }\end{array}$ 'Jona is allowed to feel like playing soccer.' 
(36) b. 'Joni se lušta smet igrat fuzbal. ${ }^{14}$ (Slovenian) Jona $_{D A T}$ REFL feels-like can $_{I N F}$ play $_{I N F}$ soccer

'Jona feels like being allowed to play soccer.'

\subsection{Aspectual/Modal Verbs and Futurates, Aspectual/Modal Verbs and ISCs}

Section 4 showed that Rivero's proposal predicts that in ISCs there should be only one possible scope relation between the desire and the necessity/possibility modal verbs and aspectual verbs, and that this prediction is incorrect. Regardless of this unrealized fixed-scope prediction-which could be dismissed if one subscribed to a clausal structure with non-fixed positions for modal/aspectual verbs-scope behavior of modal/aspectual verbs is problematic for Rivero also from the perspective of the parallel she posits between futurates and ISCs. Rivero claims that futurates and ISCs are parallel and that the modal interpretation (plan and desire) of both originates in the IMPOP-hosting AspP. Given that aspectual verbs and root-necessity/possibility modal verbs can scope over the modality (desire) in ISCs (see (31) and (34) above), this predicts that we should likewise be able to get aspectual verbs and root-necessity/possibility modal verbs scoping over the modality (plan) in futurates. However, as shown in (37-38) below, the readings with the aspectual verb and the root-necessity/possibility modal verb scoping under the futurate modality/plan are the only ones available, while the intended readings with the reverse scope do not seem to be a possibility for such sentences in either Slovenian or English.

(37) Včeraj so Yankeeji in Red Soxi začenjali (Slovenian) yesterday Aux Yankees and Red Sox $\operatorname{began}_{I M P F}$

igrat finalno serijo jutri.

play $_{I N F}$ final series tomorrow

'Yesterday, the Yankees and the Red Sox were beginning to play in the World Series tomorrow.'

\footnotetext{
14 Example (36b) sounds odd because, as we noted (2006a: 1112, fn. 14), “Overt 'feellike' examples with [ability/permission] modals sound odd, since Slovenian [ability/ permission] modals lack infinitives. The forms exist as dictionary entries but do not occur in actual speech." Examples with aspectual verbs instead of ability/permission modals, which could be used to show the same, are perfect.
} 
(37) a. 'Yesterday there was a plan for the Yankees and the Red Sox to begin playing in the World Series tomorrow.'

$$
\text { "plan > begin" }
$$

b. "\#Yesterday there began to be a plan for the Yankees to play in the World Series tomorrow./Yesterday the Yankees began to plan to play in the World Series tomorrow.' "begin > plan"

Včeraj so Yankeeji smeli jutri igrat (Slovenian) yesterday Aux Yankees $\operatorname{can}_{P A S T}$ tomorrow play $_{I N F}$

z Red Soxi.

with Red Sox

'Yesterday, the Yankees were allowed to play the Red Sox tomorrow.'

a. 'Yesterday there was a plan/it seemed that the Yankees will be allowed to play the Red Sox tomorrow.' "plan > allowed"

b. '\#Yesterday, the Yankees were allowed \{to plan to play / for someone to plan the Yankees to play \} the Red Sox tomorrow.'

"allowed > plan"

In summary, Rivero's account does not predict any of the scopal ambiguities observed above in ISCs containing modal/aspectual verbs. In fact, given that they are not observed in futurates, with which it aligns the ISC, it actually should not be able to derive them. On the other hand, these ambiguities fall out of our biclausal account naturally and we actually use them as supporting evidence for biclausality, while the unambiguity of (37-38) is not problematic for us as our analysis does not relate ISCs to futurates.

\section{Conclusion}

We argued that Rivero's aspect-based account of ISCs faces several problems. First, looking at combinability of futurates and oblique subjects, combinability of futurates and ISCs, aspect restrictions in futurates and ISCs, and hyperintensionality, we showed that the purported parallel between ISCs and futurates that Rivero's account of ISCs is based on does not hold, so the modality of the two constructions cannot originate in the same syntactic projection. Second, we presented four types of data which suggest that Rivero's analysis of prefixed ISCs 
is incorrect. And third, we showed that deriving the modality from an imperfective operator in AspP cannot account for the scope ambiguities that we observed in ISCs with modal/aspectual verbs, nor for the nonparallel behavior of futurates with modal/aspectual verbs. On the other hand, none of these data are problematic for our account of the ISC, in which the desiderativity comes from a phonologically null matrix verb FEEL-LIKE.

Rivero (2009: 190-93) presents some Bulgarian sentences which she considers biclausal because they contain a complementizer $d a$ and one or two independently inflected auxiliaries in addition to the main verb. Since Bulgarian ISCs do not have the complementizer and need not have an auxiliary, Rivero concludes that contrary to our account, ISCs are not biclausal. However, according to us, the complement of the null FEEL-LIKE predicate is not a full CP but a deficient clause (in Bulgarian no bigger than $v \mathrm{P})$, so our account does not predict the complementizer and the Infl-level auxiliaries to be possible. Moreover, note that the biclausality that Rivero assumes for her examples is by no means uncontroversial. Mišeska Tomić (2004) analyzes such constructions as monoclausal. Similarly, Rivero and Milojević Sheppard (2008: 282-83) raise an unfounded learnability/recoverability concern that had been addressed in Marušič and Žaucer (2005, 2006a, 2006b), and they also mention that unlike some other psych predicates, ISCs do not nominalize, considering this as evidence against our null-psych-verb approach (2008: 283-84). However, unlike the psych predicates that Rivero and Milojević Sheppard (2008) compare the ISC to, the predicates contained in the overt paraphrases of the ISC (containing dative-subject REFL-marked verbs such as luštati, hoteti, ljubiti, dati) likewise do not nominalize, so the comparison and the criticism are ill-founded.

In summary, Rivero's account of the ISC was refuted by three types of unfulfilled predictions. At the same time, the only empirical argument Rivero mounts against our account (i.e., the absence of the complementizer and auxiliary in the Bulgarian ISC) turns out to be a misinterpretation of our claims and, independently, based on a controversial assumption. We conclude, therefore, that our null-verb account of ISCs remains superior to the more recent aspect-based account of Rivero. This result, in turn, has several repercussions for linguistic theory. For example, on our account, the ISC offered a rare attestation of the null-verb theory's-van Riemsdijk 2002, 2012, Larson, den Dikken, and Ludlow 2006, etc.-logical possibility that null verbs can also appear as matrix verbs, in addition to the more abundantly attested cases of em- 
bedded null verbs. By questioning our account of the ISC, Rivero thus presented a challenge to the null-verb theory as a whole. Similarly, by positing that hyperintensionality can arise outside of a clausal complement, Rivero posed a challenge for the sententionalist view of hyperintensionality (e.g., Larson 2002, 2011). Moreover, Rivero's account casts doubt on the validity of our ISC-based conclusion that the minimalist model should allow linguistic structure to spell out to the PF and LF interfaces separately. By reinstating our null-verb account of the ISC, we have voided these challenges.

\section{References}

Benedicto, Elena E. (1995) "Mne ne čitaetsja: (Relativized) modality, datives, and reflexive suffixes". Penn working papers in linguistics 2(2): $1-16$.

Błaszczak, Joanna and Dorota Klimek-Jankowska. (2013) "Futures, futurates, plans, and forces". Uwe Junghanns, Dorothee Fehrmann, Denisa Lenertová, and Hagen Pitsch, eds. Formal Description of Slavic languages: Proceedings of FDSL 9. Frankfurt am Main: Peter Lang, 9-36.

Borik, Olga. (2006) Aspect and reference time. Oxford: Oxford University Press.

Butler, Jonny. (2003) "A minimalist treatment of modality". Lingua 113(10): 967-96.

Cinque, Guglielmo. (1999) Adverbs and functional heads. Oxford: Oxford University Press.

. (2004) "Restructuring' and functional structure". Adriana Belletti, ed. Structures and beyond: The cartography of syntactic structures. Vol. 3. Oxford: Oxford University Press, 132-91.

Copley, Bridget. (2002) The semantics of the future. PhD dissertation, MIT. . (2008) "The plan's the thing: Deconstructing futurate meanings". Linguistic inquiry 39(2): 261-74.

. (2011) "Causal chains for futures and futurates". Philippe de Brabanter, Mikhail Kissine, and Saghie Sharifzadeh, eds. Future times, future tenses. Oxford: Oxford University Press. Available at: http://www.academia.edu/538611/Causal_chains_for_futures_and_ futurates 
Copley, Bridget and Heidi Harley. (2009) "Futurates, directors, and have-causatives". Snippets 19: 5-6.

Demirdache, Hamida and Myriam Uribe-Etxebarria. (2004) "The syntax of time adverbs". Jacqueline Guéron and Alexander Lecarme, eds. The syntax of time. Cambridge, MA: MIT Press, 143-79.

Franks, Steven. (1995) Parameters of Slavic morphosyntax. New York: Oxford University Press.

Franks, Steven and Tracy Holloway King. (2000) A handbook of Slavic clitics. Oxford: Oxford University Press.

Heim, Irene. (1992) "Presupposition projection and the semantics of attitude verbs". Journal of semantics 9(3): 183-221.

Huddleston, Rodney. (1977) “The futurate construction". Linguistic inquiry 8(4): 730-36.

Kearns, Kate. (2000) Semantics. London: Macmillan.

Kratzer, Angelika. (1991) "Modality". Arnim von Stechow and Dieter Wunderlich, eds. Semantics: An international handbook of contemporary research. Berlin: Walter de Gruyter, 639-50.

Larson, Richard. (2002) "The grammar of intensionality". Gerhard Preyer and Georg Peter, eds. Logical form and language. Oxford: Oxford University Press, 228-62.

(2011) "Clauses, propositions, and phases". Anne-Marie DiSciullo and Cedric Boeckx, eds. The biolinguistic enterprise: New perspectives on the evolution and nature of the human language faculty. Oxford: Oxford University Press, 366-91.

Larson, Richard, Marcel den Dikken, and Peter Ludlow. (2006) "Intensional transitive verbs and abstract clausal complementation". Stony Brook University occasional papers in linguistics 1: 57-105.

Marušič, Franc. (2008) "Slovenian clitics have no unique syntactic position". Andrei Antonenko, John F. Bailyn, and Christina Y. Bethin, eds. Formal approaches to Slavic linguistics: The Stony Brook meeting. Ann Arbor: Michigan Slavic Publications, 266-81.

Marušič, Franc and Rok Žaucer. (2005) "A case for phonologically null lexical verbs". Sylvia Blaho, Luis Vicente, and Erik Schoorlemmer, eds. Proceedings of Console XIII. Leiden: Student Organisation of Linguistics in Europe, 231-48.

. (2006a) "On the intensional FEEL-LIKe construction in Slovenian: A case of a phonologically null verb". Natural language and linguistic theory 24(4): 1093-159. 
Marušič, Franc and Rok Žaucer. (2006b) “On the complement of the intensional transitive 'want'". Stony Brook occasional papers in linguistics 1: 128-51.

Mišeska Tomić, Olga. (2004) "The syntax of the Balkan Slavic future tenses". Lingua 114(4): 517-42.

Radford, Andrew. (2004) English syntax: An introduction. Cambridge: Cambridge University Press.

van Riemsdijk, Henk C. (2002) “The Unbearable Lightness of GOing: The projection parameter as a pure parameter governing the distribution of elliptic motion verbs in Germanic". Journal of comparative Germanic linguistics 5(1-3): 143-96.

- (2012) "The absent, the silent, and the audible: Some thoughts on the morphology of silent verbs". Esther Torrego, ed. Of grammar, words, and verses: In honor of Carlos Piera. Amsterdam: John Benjamins, 19-39.

Rivero, María-Luisa. (2004) “Datives and the non-active voice: Reflexive clitics in Balkan languages". Olga Mišeska Tomić, ed. Balkan syntax and semantics. Amsterdam: Benjamins, 237-67.

. (2009) "Intensionality, high applicatives, and aspect: Involuntary state constructions in Bulgarian and Slovenian". Natural language and linguistic theory 27(1): 151-96.

Rivero, María-Luisa and Ana Arregui. (2012) "Building involuntary states in Slavic". Violeta Demonte and Luise McNally, eds. Telicity, change, and state: A cross-categorial view of event structure. Oxford: Oxford University Press, 300-32.

Rivero, María-Luisa and Milena Milojević Sheppard. (2003) “Indefinite reflexive clitics in Slavic: Polish and Slovenian". Natural language and linguistic theory 21(1): 89-155.

Rivero, María-Luisa and Milena Milojević Sheppard. (2008) “Revisiting involuntary state constructions in Slovenian". Franc Marušič and Rok Žaucer, eds. Studies in formal Slavic linguistics. Frankfurt: Peter Lang, 273-89.

Spencer, Andrew and Marina Zaretskaya. (1998) "Verb prefixation in Russian as lexical subordination". Linguistics 36(1): 1-40.

Svenonius, Peter. (2004) "Slavic prefixes inside and outside the VP". Nordlyd 32(2): 205-53.

Tilkov, Dimitar, Stojan Stojanov, and Konstantin Popov. (1982-83) Gramatika na savremennija balgarski knižoven ezik. Vols. 1-3. Sofia: Bălgarska Akademija na Naukite. 
Vetter, David. (1973) "Someone solves this problem tomorrow". Linguistic inquiry 4(1): 104-08.

Žaucer, Rok. (2010) "The reflexive-introducing $n a$ - and the distinction between internal and external Slavic prefixes". Anastasia Smirnova, Vedrana Mihaliček, and Lauren Ressue, eds. Formal studies in Slavic linguistics. Newcastle upon Tyne: Cambridge Scholars Publishing, 54-102.

Research Center for Humanities

Received: June 2012

University of Nova Gorica

Revised: December 2013

Vipavska 13

SI 5000 Nova Gorica

Slovenia

franc.marusic@ung.si

rok.zaucer@ung.si 
